
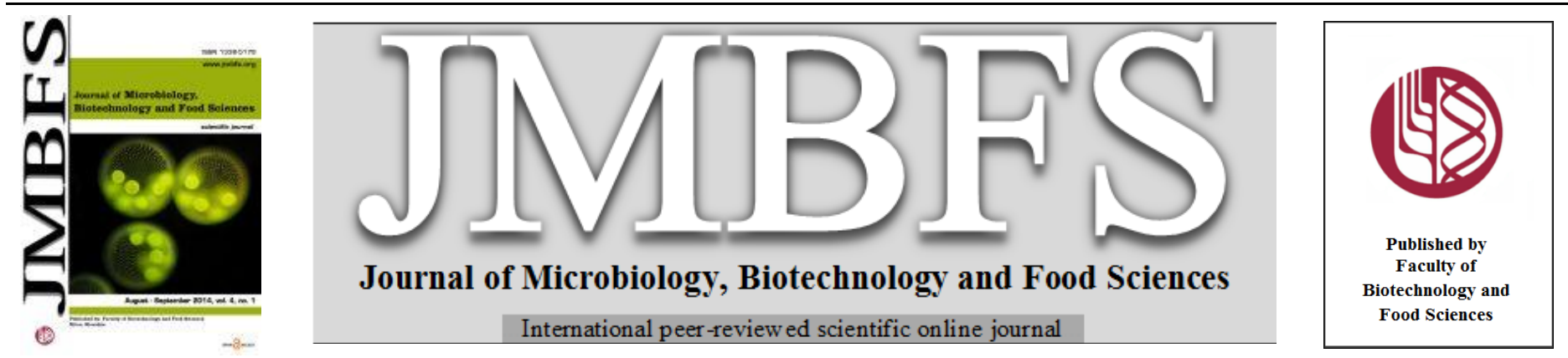

\title{
ESTIMATION OF AMOXICILLIN RESIDUES IN COMMERCIAL MEAT AND MILK SAMPLES
}

\author{
Ainee Irum ${ }^{l}$, Huma Saeed ${ }^{l}$, Shafaqat Ali ${ }^{{ }^{*}}$, Mujahid Farid ${ }^{l}$, Rushda Parveen ${ }^{l}$, Uzma Maqbool ${ }^{2}$, Rehan Ahmad ${ }^{l}$
}

\begin{abstract}
Address(es):
${ }^{1}$ Department of Environmental Sciences, Government College University, Allama Iqbal Road, Faisalabad 38000, Pakistan.

${ }^{2}$ Drug Residue Analysis Lab, Nuclear Institute for Agriculture and Biology (NIAB), Jhang Road, Faisalabad 38000, Pakistan.
\end{abstract}

*Corresponding author: shafaqataligill@yahoo.com

doi: 10.15414/jmbfs.2014.4.1.48-50

\section{ARTICLE INFO}

Received 22. 5. 2014

Revised 21. 6. 2014

Accepted 9. 7. 2014

Published 1. 8. 2014

Regular article

open $\partial_{\text {ACCESS }}$

\begin{abstract}
The present study was conducted to evaluate the extent of $\beta$ - lactam antibiotic, amoxicillin residues in market milk and meat. Samples were randomly collected from Faisalabad city, Pakistan. High Performance Liquid Chromatography (HPLC) method with inflorescent detector was used to detect, identify and quantify the amoxicillin residues in milk and meat samples. The milk samples were purified by performing a protein precipitation step, followed by derivatization. To clean up tissue samples, a liquid extraction, followed by a solidphase extraction procedure $\mathrm{C} 18(4.0 \mathrm{X} 4.6 \mathrm{~mm}, 5 \mu \mathrm{m})$ was performed. A $50 \%$ meat and $90 \%$ milk samples were found contaminated with residues. The residues of amoxicillin in milk were in range of 28 to $46 \mu \mathrm{g} / \mathrm{kg}$ and in meat were 9 to $84 \mu \mathrm{g} / \mathrm{kg}$. All of the contaminated milk and 40 out of $50 \%$ meat samples fall in maximum residue limits.
\end{abstract}

Keywords: Amoxicillin, residue, meat, milk, health risks

\section{INTRODUCTION}

Food safety is an important issue for the dairy and beef industries. A primary concern of consumers regarding food quality and safety is drug residues, particularly in food products of animal origin like milk and meat (Sundlof, 1993). This public awareness and concern have made it crucial that marketed meat and milk should be free of drug residues. The administration of antimicrobial drugs to food producing animals may lead to presence of residues in edible products. The USA Food and Drug Administration (FDA) have identified approximately 80 drugs which show residual behavior in animalderived human food (Ghidini $\boldsymbol{e t}$ al., 2002). This situation leads to more strict regulations for occurrence of antibiotic residues in animal food products.

These drugs are administered to animals by injections (intravenously, intramuscularly, or subcutaneously), orally in feed or water, topically on the skin and by intramammary and intrauterine infusions (Mitchell, 1998). The potential of drugs and antibiotics to cause allergic reactions and enhanced bacterial resistance demands for the food supply free of such residues.

The $\beta$-lactam group of antibiotics is oldest group, widely used for the treatment of infections in farm animals. Milk and meat of such animals is used without any safety measures, causing problems in dairy industries as well as for human health. Amoxicillin (AMO) is an in vitro broad spectrum antibiotic with higher ability of getting absorbed that ranges from 50 to $80 \%$ via oral administration Kosmidis et al., 1972. It reaches maximum concentration of $8 \mu \mathrm{g} / \mathrm{mL}$ about 2 hours after administration, exhibits as low as $17 \%$ binding with plasma proteins, is quickly distributed through the body and is resistant to acid produced in stomach (Kantiani et al., 2010). It acts by inhibiting the cross-linkage between the linear peptidoglycan polymer chains that make up the bacterial cell walls (Handsfield et al., 1973).

AMO is commercially available as capsules, chewable and dispersible tablets plus syrup and pediatric suspension for oral use, and as the sodium salt for intravenous administration (Abreu and Ortiz, 2003). It is equally effective in treating a wide range of Gram Positive and Gram Negative, aerobic and anaerobic bacteria to treat bacterial infections, including Haemophilus influenzae, Neisseria gonorrhoea, Escherichia coli, pneumococci, streptococci, Proteus mirabilis, Salmonella spp and certain strains of staphylococci.

AMO may cause diarrhea, indigestion, nausea, vomiting, stomach pain, headache, fever, sore throat (wikipedia.org). Beside this, antibiotics may interfere with the manufacture of several dairy products. Concentration of $1 \mathrm{ppb}$ delays starter activity during butter and yogurt making. Antibiotics also decrease the acid and flavor production associated with butter manufacture and they reduce the curdling of milk and cause improper ripening of cheese (Jones, 1999).
The maximum residue limits (MRLs) for milk and meat is $4 \mathrm{ug} / \mathrm{Kg}$ and $10 \mu \mathrm{g} / \mathrm{Kg}$ (U.S code of federal regulations, 1991) respectively.

The frequent use of antibiotics results in residues at different concentration levels due to e.g. improper observance of withdrawal times and is believed to contribute to new strains of bacteria that are resistant to many types of antibiotics, that are of legal concern worldwide (Kempe and Verachtert, 2000). Resistant pathogens have resulted due to the use and sometimes misuse of antibiotics. These resistant antimicrobial can affect not only animal health, but also public health by entering the food chain (Karraouan et al., 2009). Human who is non-target organism of these antibiotics receive different amounts of residues through milk and meat these residues can cause microbial resistance in human body. These residues can also lead to the elimination of some useful bacterial strains (Tajick and Shohreh, 2006).

The aim of the present study was to determine the concentration of amoxicillin in locally available beef meat and in milk samples. The method used was a validated HPLC method with fluorescence detection.

\section{MATERIAL AND METHODS}

\section{Materials}

Milk and lean beef samples were collected from different areas of Faisalabad. The source of Amoxicillin was commercial Amoxyl Capsules containing $78 \mathrm{mg}$ AMO/100mg. The chemicals used were Granular potassium phosphate $\left(\mathrm{KH}_{2} \mathrm{PO}_{4}\right)$, Hydro Chloric Acid $(\mathrm{HCl})$, Sodium Chloride $(\mathrm{NaCl})$, Citric Acid $\left(\mathrm{C}_{6} \mathrm{H}_{8} \mathrm{O}_{7}\right)$, Trichloroacetic Acid $\left(\mathrm{CCl}_{3} \mathrm{COOH}\right)(\mathrm{TCA})$, Methanol $\left(\mathrm{CH}_{3} \mathrm{OH}\right)$ Acetonitrile $\left(\mathrm{CH}_{3} \mathrm{CN}\right)$, Diethyl ether $\left(\mathrm{C}_{4} \mathrm{H}_{10} \mathrm{O}\right)$ Formaldehyde $\left(\mathrm{CH}_{2} \mathrm{O}\right)$. $0.01 \mathrm{M}$ Phosphate Solution, 7\% Formaldehyde Solution, 2\%, 20\%, 75\% TCA Solution, 0.4M Citric Acid Solution, standard solutions were prepared with HPLC grade deionized water. Stock standard solution $(1 \mathrm{mg} / \mathrm{mL})$ was prepared which was stable for at least 1 month. An intermediate standard solution $(5 \mu \mathrm{g} / \mathrm{mL})$ followed by the working standard solution $(50 \mathrm{ng} / \mathrm{mL})$ was prepared daily by dilution of the working standard solution with mobile phase. Spiking solutions were also made by this method

\section{Secreeing of meat samples for Amoxicillin residues}

Skin and excess fats were removed and discarded. Cleaned lean samples were cut into small pieces, placed in plastic bags, sealed and stored in freezer at $-70^{\circ} \mathrm{C}$. 


\section{Sample extraction}

Meat frozen samples were partially thawed at room temperature $\left(23^{\circ} \mathrm{C}\right)$ for about $30 \mathrm{~min}$ and were blended in a food processor 4 times for $3 \mathrm{~min}$ at high speed. A uniform paste-like consistency was obtained by stirring the material after each intermittent blending. The prepared tissues were weighed $(5.0 \mathrm{~g})$ into an empty dry clean test tube $(50 \mathrm{~mL})$.

\section{Initial Extraction}

$0.01 \mathrm{M}$ phosphate buffer solution $(\mathrm{pH} 4.5,20 \mathrm{~mL})$ was added for initia extraction. Mixture was homogenized at $10000 \mathrm{rpm}$ for $90 \mathrm{~s}$ on a vortex mixer. Homogenized mixture was centrifuged at $4000 \mathrm{rpm}$ for $10 \mathrm{~min}$ and decantated the supernatant into another centrifuge tube $(50 \mathrm{~mL})$. Another buffer solution $(20 \mathrm{~mL})$ was added into the residues homogenized and centrifuged as before and the supernatant was combined with first extract. Supernatant was filtered through glass wool plug and a filtrate $(40 \mathrm{~mL})$ was obtained. To the filtrate $75 \%$ TCA solution $(1 \mathrm{~mL})$ was added, and mixed on a vortex mixer for $30 \mathrm{~s}$ and centrifuged at $4000 \mathrm{rpm}$ for $20 \mathrm{~min}$ for deproteinization. The supernatant was filtered again through glass wool plug. After conditioning with methanol $(5 \mathrm{~mL})$ each cartridge was washed with $20 \%$ TCA solution $(2 \mathrm{~mL})$. At a flow rate of $2 \mathrm{~mL} / \mathrm{min}$ sample filtrate was passed through the cartridge and the cartridge was washed with $2 \%$ TCA solution $(2 \mathrm{~mL})$ and distilled water $(2 \mathrm{~mL})$. Residues in cartridge were collected in $50 \%$ acetonitrile $(2.0 \mathrm{~mL})$ using $10 \mathrm{~mL}$ test tube, covered with aluminum foil and stored in refrigerator overnight.

\section{Derivatization and Extraction}

Stored eluate was mixed with $20 \%$ TCA solution $(0.2 \mathrm{~mL})$ on vortex mixer for $15 \mathrm{~s}$. After that formaldehyde solution $(0.2 \mathrm{~mL})$ was added and mixed on a vortex mixer for 30s. Mixture was heated in boiling water bath for $30 \mathrm{~min}$ and cooled to room temperature in cold water bath. $\mathrm{NaCl}(0.5 \mathrm{~g})$ was added and mixed on Vortex mixer for $1 \mathrm{~min}$ to make the amoxicillin derivatives florescent. The derivative mixer was further cleaned up by using liquid-liquid partition. For this purpose, diethyl ether $(3 \mathrm{~mL})$ was added 3 times. The ether layer was removed each time after mixing on Vortex mixer for $1 \mathrm{~min}$, and centrifuged at 2000rpm for $3 \mathrm{~min}$. Ether extracts were combined in glass tube $(15 \mathrm{~mL})$. Tube contents were evaporated to dryness using water bath. Mobile phase $(0.5 \mathrm{~mL})$ was added to each tube and mixed on Vortex mixer to reconstitute the residues.

\section{Screening of milk samples for Amoxicillin residues}

\section{Extraction and Clean up}

An aliquot of milk $(2.5 \mathrm{~mL})$ was added with water $(0.1 \mathrm{~mL}), 20 \%$ Trichloroacetic acid $(0.5 \mathrm{~mL})$ and of Acetonitrile $(0.5 \mathrm{~mL})$. After each addition the sample was shaked for about $1 \mathrm{~min}$ followed by centrifugation at 3000rpm for $15 \mathrm{~min}$. The supernatant was filtered with a $0.45 \mu \mathrm{m}$ minifilter. The filtrate was added with $30 \% \mathrm{w} / \mathrm{v}$ TCA $(0.6 \mathrm{~mL})$ and $0.4 \mathrm{M}$ citric acid $(1 \mathrm{~mL})$ solution containing formaldehyde $(7 \% \mathrm{w} / \mathrm{v})$ was added. The samples were vortexed for $15 \mathrm{~s}$, and heated in water bath at $100^{\circ} \mathrm{C}$ for 1 hour and allowed to cool at room temperature. After cooling, the mobile phase was added to the sample to make the volume up to $3.5 \mathrm{~mL}$.

\section{HPLC Conditions}

HPLC system of Hitache-L-2000 with EZ Start software equipped with florescent detector Hitachi-L-2485 at excitation of 354nm and emission of 445nm, Oven temperature $25{ }^{\circ} \mathrm{C}$ and Delivery pump LC-10 AS was used. Sample/standard injection volume was $20 \mu \mathrm{L}$. HPLC separation was performed at an Inertsil Octadecylsilane-3 C18, $4.04 .6 \mathrm{~mm}$, and $5 \mu \mathrm{m}$ USA using a mobile phase of ACN: $\mathrm{KH}_{2} \mathrm{PO}$ with $85: 15$ concentrations at a flow rate of $1 \mathrm{~mL} / \mathrm{min}$.

\section{LC Analysis and Quantification}

Aliquots of the final extract $(50 \mathrm{~mL})$ were injected into the LC vials. $20 \mu \mathrm{L}$ of the extract was injected into the column and analyzed at $1.0 \mathrm{~mL} / \mathrm{min}$. Amoxicillin standard solution of $10 \mathrm{ppb}$ was run through the HPLC and a standard curve at retention time 2.193 for meat and at 6.060 for milk was obtained (Table 1).

Table 1 Retention times and peak areas of amoxicillin standards and spiked milk and meat samples

\begin{tabular}{lcc}
\hline Matrix & Retention time (min) & Peak Area (mAv) \\
\hline Amoxicillin Std 1 & 2.193 & \\
\hline Amoxicillin Std 2 & 6.060 & 2460165 \\
\hline Spiked milk sample 1 & 5.970 & 246107 \\
\hline Spiked milk sample 2 & 5.967 & 565431 \\
\hline Spiked milk sample 3 & 6.073 & 13171225 \\
\hline Spiked milk sample 4 & 6.087 & 98619581 \\
\hline Spiked meat sample 5 & 2.117 & 108592 \\
\hline
\end{tabular}

Amoxicillin residues in sample extracts were identified by comparing the peak retention time/area with standard chromatograms. Residues were quantified by external as well as internal (spiked) standard method.

\section{RESULTS AND DISCUSSION}

The standard curves of amoxicillin were constructed to determine the AMO residues in each sample of milk and meat. $10 \mathrm{ppm}$ standard of the antibiotic showed peak at Retention Time 2.193. This retention time was also confirmed by spiking meat sample with amoxicillin standard. The beef sample showed retention time at 2.117 (Table 1) after spiking. No milk sample showed any peak at 2.193 (Table 2). In order to confirm these observations co-chromatography was done (Table 1).

Table 2 Results of meat samples according to Amoxicillin Standard 1

\begin{tabular}{lccc}
\hline No of Samples & $\begin{array}{c}\text { Amoxicillin } \\
\text { residue }\end{array}$ & $\begin{array}{c}\text { Retention Time } \\
(\mathbf{m i n})\end{array}$ & Peak Area \\
\hline Sample 1 & + ve & 2.120 & 174164 \\
\hline Sample 2 & -ve & - & - \\
\hline Sample 3 & -ve & - & - \\
\hline Sample 4 & +ve & 2.107 & 318352 \\
\hline Sample 5 & -ve & - & - \\
\hline Sample 6 & +ve & 2.220 & 79650 \\
\hline Sample 7 & -ve & - & - \\
\hline Sample 8 & +ve & 2.220 & 33211 \\
\hline Sample 9 & -ve & - & - \\
\hline Sample 10 & +ve & 2.107 & 303223 \\
\hline
\end{tabular}

AMO in methanol showed RT of 2.193 whereas in co-chromatography, it depicted itself at RT of 6.06 after spiking. This is because, AMO did not undergo any chemical reaction in methanol spiking coupled with extraction/ cleanup in milk results in peak shifting from 2.193 to 6.06. Increase in area percentage at RT of 6.06 for the samples, spiked with 50ppb to 1000ppm (Table 1) also confirmed the presence of AMO in spiked milk samples.

$\underline{\text { Table } 3 \text { Results of milk samples according to Amoxicillin standard } 2}$

\begin{tabular}{lccc}
\hline No of Samples & $\begin{array}{c}\text { Amoxicillin } \\
\text { presence }\end{array}$ & $\begin{array}{c}\text { Retention Time } \\
(\text { min) }\end{array}$ & Peak Area \\
\hline Sample 1 & +ve & 5.963 & 681591 \\
\hline Sample 2 & +ve & 5.980 & 694050 \\
\hline Sample 3 & +ve & 5.957 & 640449 \\
\hline Sample 4 & -ve & - & - \\
\hline Sample 5 & +ve & 5.960 & 1443733 \\
\hline Sample 6 & +ve & 5.927 & 1207776 \\
\hline Sample 7 & +ve & 6.060 & 615244 \\
\hline Sample 8 & +ve & 6.073 & 681382 \\
\hline
\end{tabular}

At RT of $2.193 \mathrm{~min}$ and $6.06 \mathrm{~min}$ for AMO, all the chromatograms of meat and milk samples were evaluated. 50\% meat samples (Table 2) and $90 \%$ milk samples (Table 3) were found positive for AMO residues. $40 \%$ meat samples were found above MRL and all contaminated milk samples were above MRL. Results of this study confirmed that AMO had the potential to cause short term drug residues (Musser et al., 2001).

Concentration of amoxicillin residues in percentage and microgram per kilogram is shown in Table 4.

$50 \%$ meat samples were found contaminated. These results confirmed that the fate of any substance towards deposition is minimum. In addition AMO is administered to lactating cattle by intravenous, subcutaneous, intramammary and intramuscularly routes. This process resulted in milk that is also known as "waste milk" (Chik et al.,1975) , not acceptable for human consumption, which may be fed to calves in dairy farms (Chardavoyne et al., 1979; Chik et al., 1975; Kesler,1981; and Yndestad, 1980) This fact is in line with the study of Guest and Paige, 1991; and Dasser and Wilcke, 1989, that the cause of drug residues in meat has been identified as the result of feeding of cattle with the milk containing antibiotics.

On the other hand $90 \%$ milk samples were found positive for the residues of AMO. These results showed that the fate of any substance is to flush out from body via body fluids like urine and milk in mammals. The presence of residues indicates the increase of awareness among the animal owners which might be due 
to the increased education levels and increased veterinarian visits during animal treatment (Zubeir and Owni, 2009). Furthermore the majority of instances for the presence of antibiotics residues in milk may be associated with extra dosage treatment even after withholding time. This fact is in accordance with the findings of Scot et al., 1991, who reported that occurrence of residues was more common after extra dosage of drug.

Table $4 \%$ and $\mu \mathrm{g} / \mathrm{Kg}$ concentration of Amoxicillin residues in Samples

\begin{tabular}{lcc}
\hline Samples & Amoxicillin Conc. $\%$ & $\begin{array}{c}\text { Amoxicillin Conc. } \\
\boldsymbol{\mu g} / \mathbf{K g}\end{array}$ \\
\hline Beef meat sample 1 & $46 \%$ & 46 \\
\hline Beef meat sample 2 & $0 \%$ & 0 \\
\hline Beef meat sample 3 & $0 \%$ & 0 \\
\hline Beef meat sample 4 & $84 \%$ & 84 \\
\hline Beef meat sample 5 & $0 \%$ & 0 \\
\hline Beef meat sample 6 & $21 \%$ & 21 \\
\hline Beef meat sample 7 & $0 \%$ & 0 \\
\hline Beef meat sample 8 & $9 \%$ & 9 \\
\hline Beef meat sample 9 & $0 \%$ & 0 \\
\hline Beef meat sample 10 & $80 \%$ & 80 \\
\hline Milk sample 1 & $27 \%$ & 27 \\
\hline Milk sample 2 & $28 \%$ & 28 \\
\hline Milk sample 3 & $26 \%$ & 26 \\
\hline Milk sample 4 & $0 \%$ & 0 \\
\hline Milk sample 5 & $58 \%$ & 58 \\
\hline Milk sample 6 & $49 \%$ & 49 \\
\hline Milk sample 7 & $25 \%$ & 25 \\
\hline Milk sample 8 & $27 \%$ & 27 \\
\hline
\end{tabular}

The other parameters that effect the concentration are dose level being administered, the time interval between two consecutive treatments and the time for what the animal is exposed to specific antibiotic (Wang et al., 2003). This can also be a reason for the presence of drug residues.

On contrary half meat samples were found uncontaminated. One possible reason for the absence of residues may be that the samples were taken from the animals not pretreated with AMO. The reported retention time of AMO in meat is approximately days. The absence of AMO residues in $50 \%$ meat samples would be due to greater time period between treatments to slaughter. Negative results for residues in half meat samples may be because of the fact that the collected samples were from muscles while liver had 5 to 12 fold greater concentration of residues than kidneys and muscles (Korsrued et al., 1993). In addition the with drawl period of AMO in muscles fall below the MRL after the withdraw period of 10 days. This fact might be the reason that $10 \%$ meat samples were found below MRL. Furthermore the majority of instances for the absence of antibiotic residues in meat is due to unequal drug concentration in muscles because of many physiological factors such as blood flow, capillary density and capillary permeability (Chou et al., 2001).

While $10 \%$ milk samples were found negative for AMO residues. Absence of AMO residues in milk samples may be due to mixing of milk from different cattle in dairy farms (Zubeir and Owni, 2009). The reported retention time of AMO in milk is approximately 3 days (Harrison et al., 1994). 10\% uncontaminated milk samples may be attributed to the greater time period between treatment to milking or may be that such samples were collected from untreated animals.

The quantitative determination of AMO represents an analytical challenge, due to its amphoteric nature and high polarity the drug is difficult to extract with organic solvents and elute among other polar endogenous substances

\section{CONCLUSION}

As a nut shell the presence of AMO residues in 50\% meat and $90 \%$ milk samples was significant, which may indicate that the product has been obtained from an animal with serious infection, may results in immediate consumer health problems.

Acknowledgments: We thank Mrs. Shumaila, Lecturer in Environmental Sciences (GCUF), Mrs. Sadia Mehboob Junior scientist, Mr. Anwar ul Haq Assistant of principal scientist, Mr. Tabbassum, Lab attendant, Lab of Veterinary Drug Residues, NIAB (National Institute for Agriculture and Biology) Faisalabad, for moral encouragement and technical help and Lab of Veterinary Drug Residues, NIAB for providing us chemicals and instruments.

\section{REFERENCES}

ABREU, L.R.P., ORTIZ, R.A.M. 2003. HPLC determination of amoxicillin comparative bioavailability in healthy volunteers after a single dose administration. Pharm. Pharmaceut. Science, 6(2), 223-230.

DRESSER, W.R., WILCKE, J.R. 1989. Drug residues in food Animals. Journal of the American Veterinary Medical Association, 194, 1700-1710.
GHIDINI, S.M., ZANARDI, E., VARISCO, G., CHIZZOLINI, R. 2002. Prevalence of molecules of $\beta$ - lactam antibiotics in bovine milk. Vet. di Parma., $22,245-252$.

GUEST, G.B., PAIGE, J.C. 1991. The magnitude of the tissue residue problem with regard to consumer needs. Journal of the American Veterinary Medical Association, 198, 805-808

HANDSFIELD, H.H., CLARK, H. JAMES, F., HOLMES, K.K., TURCK, M. 1973. Amoxicillin, a new penicillin antibiotic. Antimicrobial Agents Chemotherapy, 3, 262-265. http://dx.doi.org/10.1128/aac.3.2.262

CHARDAVOYNE, J.E., IBEAWUCHI, J.A., KESLER, E.M., BORLAND, K.M. 1979. Waste milk from antibiotic treated cows as feed for young calves. Journal of Dairy Science, 62, 1285-1289. http://dx.doi.org/10.3168/jds.s0022. 0302(79)83413-X

CHIK, A.B., ACHACOSO, A.S., EVANS, D.L., RUSOFF, L.L. 1975. Growth and feed efficiency of young calves fed milk replacer, "waste" milk, or fermented colostrum. Journal of Dairy Science, 58, 742.

CHOU, C.C., WEBB, A.I., BROWN, M.P., GRONWALL, R., VICKROY, T.W. 2001. Continuous measurement of caffeine and two metabolites in blood and skeletal muscle of unrestrained adult horses by semi-automated in vivo microdialysis. Journal of Veterinary Pharmacology and Therapeutics, 24, 405414. http://dx.doi.org/10.1046/j.1365-2885.2001.00364.x

JONES, G.M. 1999. On farm test for drug residues in milk, Virginia cooperative extension, Knowledge for the common wealth, Virginia Polytechnic and State University, U.S.A.

KANTIANI, L., FARRE, M., FREIXIEDAS, J.M.G., BARCELO, D. 2010 Development and validation of a pressurised liquid extraction liquid chromatography-electrospray-tandem mass spectrometry method for $\beta$-lactams and sulfonamides in animal feed. Journal of Chromatography A, 1217(26), 4247-4254. http://dx.doi.org/10.1016/j.chroma.2010.04.029

KARRAOUAN B, BOUCHRIF, B., ZIYATE, N., TALMI, A., YAHIA, K.I.S., COHEN, N., FASSOUANE, A. 2009. Evaluation of multi-plate microbial assay for the screening of antibacterial residues in poultry muscle. Scientific Research, 35(2), 311-317.

KEMPE, M., VERACHTERT, B. 2000. Cartridges with molecularly imprinted recognition elements for antibiotic residues monitoring in milk cream. Pure and Applied Biochemistry, Lunds Universitét Centre for Chemistry and Chemical Engineering Getingevagen, Lund Sweden, 1-10.

KESLER, E.M. 1981. Feeding mastitic milk to calves. Dairy Science, 64, 719 723. http://dx.doi.org/10.3168/jds.s0022-0302(81)82639-2

KOSMIDIS, J., WILLIANS, D., ANDREWS, J. 1972. Amoxicillin pharmacology, bacteriology and clinical studies. Clinical Practice, 26, 341-46. MITCHELL, J.M., GRIFFITHS, M.W., MCEVEN, S.A., MCNAB, W.B., YEE, J. 1998. Antimicrobial drug residues in milk and meat: causes, concerns, prevalence, regulations, tests, and test performance. Journal of Food Protection ${ }^{\circledR}, 61(6), 742-756$.

MUSSER, J.M.B., ANDERSON, K.L., RUSHING, J.E., MOATS, W.A. 2001. Potential for milk containing penicillin $\mathrm{G}$ or amoxicillin to cause residues in calves. Journal of Dairy Sciences, 84, 126-133. http://dx.doi.org/10.3168/jds.s0022-0302(01)74460-8

NEAL, M.J. 2002. Medical Pharmacology at a Glance. 4th ed. Blackwell Science, Oxford, UK.

SCOT, A.M., WILlLIAM, D., ALAN, H. 1991. Antibiotic residues in the milk of cows treated under label and extra label conditions. Proceedings of the 6th International Symposium on Veterinary Epidemiology and Economics.

SUNDLOF, S.F. 1993. Antimicrobial drug residues in food-producing animals Pages 569-591 in Antimicrobial Therapy in Veterinary Medicine. J. F. Prescott and J. D. Baggot, ed. Iowa State University Press, Ames, IA.

U.S. Code of Federal Regulations (1991) Part 21, Section 556.38, Amoxicillin U.S. Government Printing Office, Washington, DC.

WANG, J.H., CHAO, M.R., CHANG, M.H., KUO, T.F. 2003. Liquid chromatographic determination of amoxicillin residues in grouper muscle following oral administration of the veterinary drug. The Veterinary Journal, 35(1), 21-28.

YNDESTAD, M., HELMEN, P. 1980. Antibiotikaholdig melk som for til unge kalver-en undersokelse over en del helsemessige forhold etter periodevis tilforsel a' penicillin org.

ZUBEIR, E.L., IBTISAM, E.M., EL OWNI, O. A. O. 2009. Antimicrobial resistance of Bacteria associated with raw milk contaminated by chemical preservatives. Dairy and Food Sciences, 4(1), 65-69. 